Article

\title{
Computational and Spectroscopic Studies of Carbon Disulfide
}

\author{
Indri B. Adilina ${ }^{1}$, Fauzan Aulia ${ }^{1}$, Muhammad A. Fitriady ${ }^{1}$, Ferensa Oemry ${ }^{2} \mathbb{D}$, \\ Robert R. Widjaya ${ }^{1}$ and Stewart F. Parker ${ }^{3, *}$ (D) \\ 1 Research Center for Chemistry, Indonesian Institute of Sciences, Kawasan Puspiptek Serpong, \\ Tangerang Selatan, Banten 15314, Indonesia; indri.badria.adilina@lipi.go.id (I.B.A.); \\ fauzan.aulia@lipi.go.id (F.A.); muhammad.arifuddin.fitriady@lipi.go.id (M.A.F.); \\ robert.ronal.widjaya@lipi.go.id (R.R.W.) \\ 2 Research Center for Physics, Indonesian Institute of Sciences, Kawasan Puspiptek Serpong, \\ Tangerang Selatan, Banten 15314, Indonesia; ferensa.oemry@lipi.go.id \\ 3 ISIS Facility, STFC Rutherford Appleton Laboratory, Chilton, Didcot, Oxon OX11 0QX, UK \\ * Correspondence: stewart.parker@stfc.ac.uk; Tel.: +44-1235-6182
}

Academic Editors: Paulo Ribeiro-Claro and Mariela Nolasco

check for updates Received: 28 March 2020; Accepted: 15 April 2020; Published: 20 April 2020

\begin{abstract}
The vibrational spectroscopy of $\mathrm{CS}_{2}$ has been investigated many times in all three phases. However, there is still some ambiguity about the location of two of the modes in the solid state. The aim of this work was to locate all of the modes by inelastic neutron scattering (INS) spectroscopy, (which has no selection rules), and to use periodic density functional theory to provide a complete and unambiguous assignment of all the modes in the solid state. A comparison of the observed and calculated INS spectra shows generally good agreement. All four of the $v_{2}$ bending mode components are calculated to fall within $14 \mathrm{~cm}^{-1}$. Inspection of the spectrum shows that there are no bands close to the intense feature at $390 \mathrm{~cm}^{-1}$ (assigned to $v_{2}$ ); this very strongly indicates that the $A_{u}$ mode is within the envelope of the $390 \mathrm{~cm}^{-1}$ band. Based on a simulation of the band shape of the $390 \mathrm{~cm}^{-1}$ feature, the most likely position of the optically forbidden component of the $v_{2}$ bending mode is $393 \pm 2 \mathrm{~cm}^{-1}$. The calculations show that the optically inactive $A_{u}$ translational mode is strongly dispersed, so it does not result in a single feature in the INS spectrum.
\end{abstract}

Keywords: carbon disulfide; inelastic neutron scattering; Raman spectroscopy; infrared spectroscopy; density functional theory

\section{Introduction}

Carbon disulfide, $\mathrm{CS}_{2}$, changed from being a laboratory curiosity in the mid-1800s when it was first used industrially for the vulcanization of rubber. Since then, it has had many commercial uses. The current major uses are for the production of viscose rayon and cellophane and as a solvent in adhesives and cleaners [1].

The vibrational spectroscopy of $\mathrm{CS}_{2}$ has been investigated many times in all three phases [2-12]. However, there is still some ambiguity about the location of two of the modes in the solid state. The aim of this work was to locate all of the modes by inelastic neutron scattering (INS) spectroscopy, which has no selection rules [13], and to use periodic density functional theory to provide a complete and unambiguous assignment of all the modes in the solid state.

\section{Results}

In the solid state, the crystal is orthorhombic ( $\mathrm{Cmca}$ ) with two molecules in the primitive unit cell, both on sites of $C_{2 h}$ symmetry [14,15]; see Figure 1 . Figure 2 shows the correlation diagram for $\mathrm{CS}_{2}$ 
and that, at the $\Gamma$-point in the Brillouin zone (where the infrared and Raman active modes occur), the modes comprise:

$\left\{A_{g}+B_{3 g}\right\} v_{1}$ symmetric stretch, $\left\{A_{u}+B_{1 u}+B_{2 u}+B_{3 u}\right\} v_{2}$ bend,

$\left\{B_{1 u}+B_{2 u}\right\} v_{3}$ asymmetric stretch, $\left\{A_{g}+B_{1 g}+B_{2 g}+B_{3 g}\right\}$ libration,

$\left\{B_{1 g}+B_{2 g}\right\}$ translation along $z,\left\{A_{u}+B_{1 u}+B_{2 u}+B_{3 u}\right\}$ translation along $x, y$

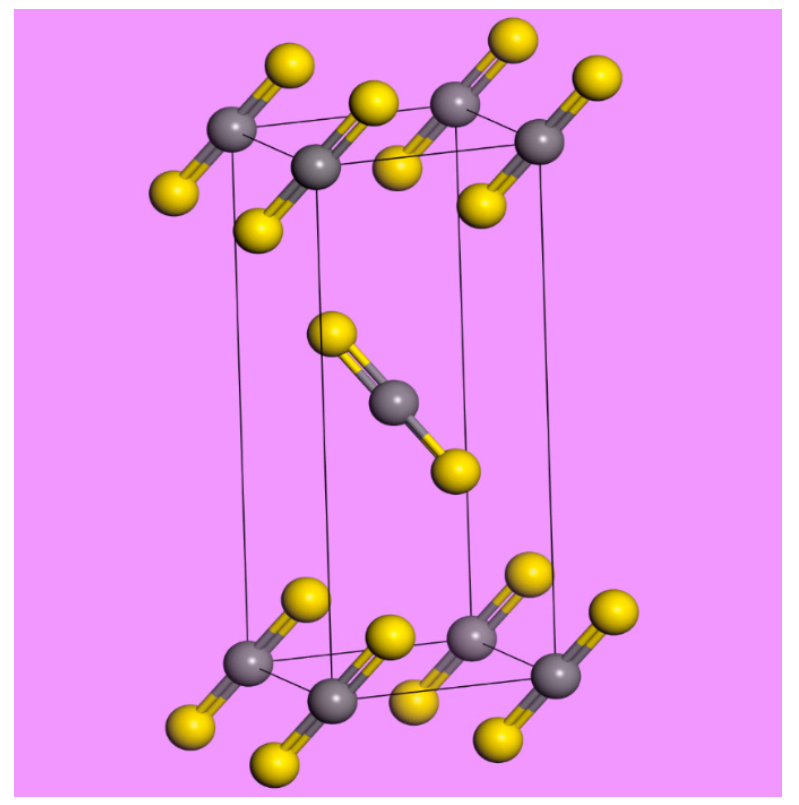

Figure 1. The primitive unit cell of carbon disulfide. Grey = carbon, yellow = sulfur.

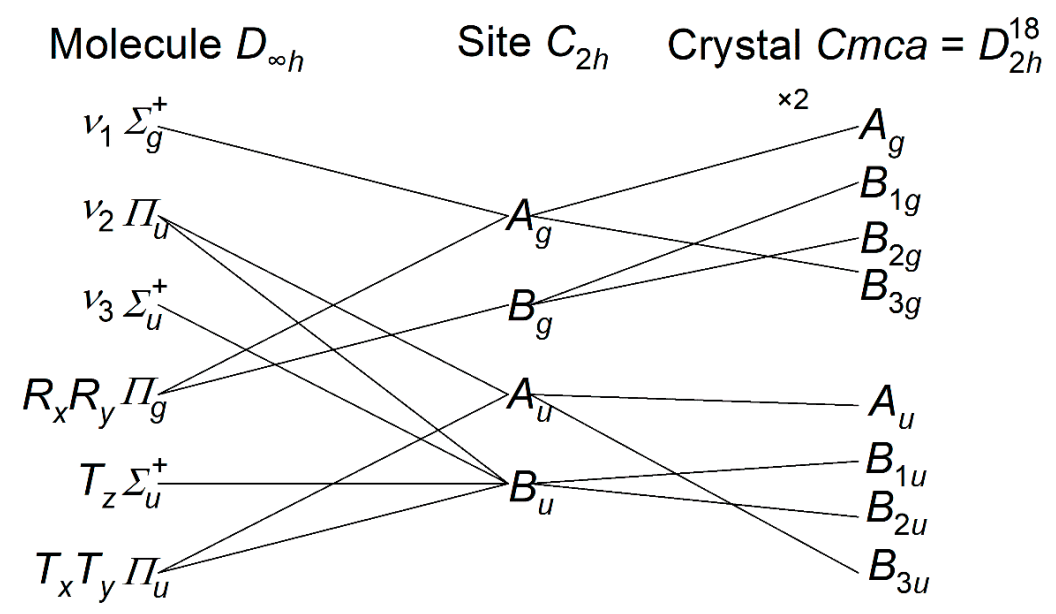

Figure 2. Correlation table for carbon disulfide in the solid state. $R=$ libration, $T=$ translation.

In addition, there are three acoustic translational modes that have zero energy at the $\Gamma$-point, but non-zero elsewhere in the Brillouin zone. These are not observable by infrared or Raman spectroscopy; however, INS can measure these [10,11]. All $g$ modes are Raman active; $B_{1 u}, B_{2 u}, B_{3 u}$ are infrared active, and $A_{u}$ is inactive in both the infrared and the Raman. Note that all modes are allowed in the INS spectrum.

Figure 3 shows the infrared, Fourier transform Raman (FT-Raman), and INS spectra. The infrared and Raman spectra are in agreement with those previously published [7], and the INS spectrum has not been seen previously. The internal fundamental modes are clearly seen at $1494 \mathrm{~cm}^{-1}\left(v_{3}\right.$ asymmetric stretch), $655 \mathrm{~cm}^{-1}$ ( $v_{1}$ symmetric stretch), and $390 \mathrm{~cm}^{-1}$ ( $v_{2}$ bend). The external (lattice) modes all occur 
below $150 \mathrm{~cm}^{-1}$. The remaining features are: $v_{3}+$ lattice $\left(1586 \mathrm{~cm}^{-1}\right), v_{1}+v_{2}\left(1066 / 1052 \mathrm{~cm}^{-1}\right), 2 v_{2}$, $\left(788 \mathrm{~cm}^{-1}\right)$, and $v_{2}+$ lattice $\left(476 / 440 \mathrm{~cm}^{-1}\right)$. Table 1 lists the fundamental modes.

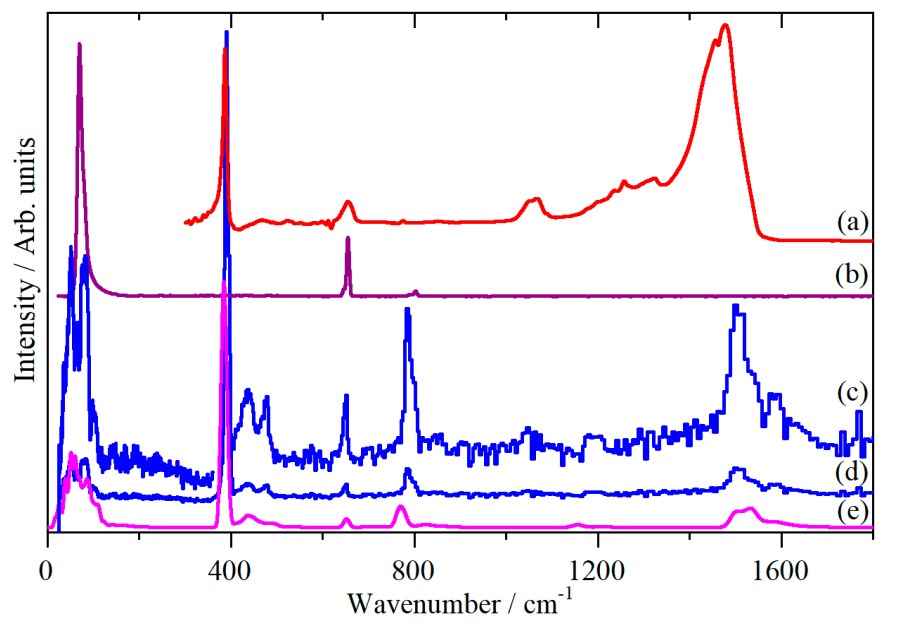

Figure 3. Vibrational spectra of solid $\mathrm{CS}_{2}$. (a) infrared at $208 \mathrm{~K}$, (b) FT-Raman at $\sim 77 \mathrm{~K}$, (c) INS at $20 \mathrm{~K}, \times 5$ ordinate expansion, (d) INS at $20 \mathrm{~K}$, and (e) INS spectrum generated from a periodic density functional theory (DFT) calculation of $\mathrm{CS}_{2}$.

Table 1. Observed and calculated (at the $\Gamma$-point) transition energies and intensities of the fundamental modes of $\mathrm{CS}_{2}$.

\begin{tabular}{|c|c|c|c|c|c|c|c|}
\hline DFT & & & & INS $^{1}$ & Infrared & Raman & Description \\
\hline$/ \mathrm{cm}^{-1}$ & Symmetry & $\begin{array}{c}\text { Infrared } \\
/ \text { Debye }^{2} \AA^{-2} \mathrm{amu}^{-1}\end{array}$ & $\begin{array}{c}\text { Raman } \\
/ \AA^{4} \mathbf{a m u}^{-1}\end{array}$ & $/ \mathrm{cm}^{-1}$ & $/ \mathrm{cm}^{-1}$ & $/ \mathrm{cm}^{-1}$ & \\
\hline 0.0 & $B_{2 u}$ & 0.000 & 0.0 & & & & Acoustic \\
\hline 0.0 & $B_{1 u}$ & 0.000 & 0.0 & & & & Acoustic \\
\hline 0.0 & $B_{3 u}$ & 0.000 & 0.0 & & & & Acoustic \\
\hline 52.0 & $A_{u}$ & 0.000 & 0.0 & 51 & & & Translation \\
\hline 69.7 & $B_{1 u}$ & 0.007 & 0.0 & & 66.5 [9] & & Translation \\
\hline 78.1 & $B_{2 u}$ & 0.007 & 0.0 & & 68.2 [9] & & Translation \\
\hline 81.9 & $A_{g}$ & 0.000 & 231.0 & & & 75 [7] & Libration \\
\hline 85.3 & $B_{1 g}$ & 0.000 & 21.9 & & & 79 [7] & Libration \\
\hline 85.6 & $B_{3 g}$ & 0.000 & 23.2 & & & 79 [7] & Libration \\
\hline 100.9 & $B_{2 g}$ & 0.000 & 109.8 & & & 85 [7] & Libration \\
\hline 378.3 & $B_{3 u}$ & 0.202 & 0.0 & & 388.7 [8] & & $v_{2}$ bend \\
\hline 384.0 & $B_{2 u}$ & 0.197 & 0.0 & & 393.4 [8] & & $v_{2}$ bend \\
\hline 384.5 & $A_{u}$ & 0.000 & 0.0 & & & & $v_{2}$ bend \\
\hline 392.3 & $B_{1 u}$ & 0.225 & 0.0 & 390 vs & $400.1[8]$ & & $v_{2}$ bend \\
\hline 653.1 & $A_{g}$ & 0.000 & 913.1 & $651 \mathrm{w}$ & & $655 \mathrm{~s}$ & $v_{1}$ symmetric stretch \\
\hline 653.9 & $B_{3 g}$ & 0.000 & 68.2 & & & $646 \mathrm{~m}$ & $v_{1}$ symmetric stretch \\
\hline 1494.6 & $B_{1 u}$ & 42.570 & 0.0 & $1507 \mathrm{w}$ & 1479 vs & & $v_{3}$ asymmetric stretch \\
\hline 1536.3 & $B_{2 u}$ & 10.132 & 0.0 & $1540 \mathrm{w}$ & $1530 \mathrm{sh}$ & & $v_{3}$ asymmetric stretch \\
\hline
\end{tabular}

There have been several attempts at detailed assignments of the spectra by lattice dynamics; however, these have all been based on empirical force field models $[7,10,11,16,17]$. Figure 3e shows the INS spectrum generated from a periodic density functional theory (DFT) calculation of the primitive unit cell, which includes the effect of vibrational dispersion (the variation of transition energy with wavevector). It can be seen that there is generally good agreement. Table 1 also lists the transition energies of the modes (and their symmetry) at the $\Gamma$-point in the Brillouin zone (where the infrared and Raman active modes are observed).

The calculations show that the inactive $A_{u}$ component of the $v_{2}$ bend quartet is almost coincident with one of the allowed modes. The observed modes are $\sim 10 \mathrm{~cm}^{-1}$ higher in energy, but the separation between the highest and lowest member, for both the observed and calculated transition energies, is 
almost the same: 11.4 and $14.0 \mathrm{~cm}^{-1}$, respectively. The full width at half maximum of the very strong INS band at $390 \mathrm{~cm}^{-1}$ is $11.9 \mathrm{~cm}^{-1}$, and there are no other features close by. As all four components of $v_{2}$ will have similar INS intensity (because the motion is the same in each case, only the phasing differs, and this is confirmed by the ACLIMAX [18] calculation of the individual intensities), this very strongly indicates that the $A_{u}$ mode is within the envelope of the $390 \mathrm{~cm}^{-1}$ band.

Figure 4 presents a detailed comparison of the observed and calculated INS spectra in the low energy region. It is evident that there is a considerable difference between the full dispersion calculation, $4 \mathrm{~b}$, and the $\Gamma$-point only calculation, $4 \mathrm{c}$, demonstrating that there is significant dispersion present, as seen for the acoustic modes by inelastic coherent neutron scattering from a single crystal [11]. The calculated dispersion curves are shown in Figure 5. It can be seen that all of the modes in the region below $150 \mathrm{~cm}^{-1}$ exhibit significant dispersion, which makes the association of specific features in the INS spectrum, in this region, with a particular mode meaningless. The "missing" translational mode is calculated to be at $52 \mathrm{~cm}^{-1}$ at the $\Gamma$-point, but disperses over the range $20-80 \mathrm{~cm}^{-1}$; thus, it makes a contribution to the structured peak at $51 \mathrm{~cm}^{-1}$, but this also includes significant contributions from acoustic translational modes. This is apparent from the additional peaks at 26 and $39 \mathrm{~cm}^{-1}$ in the full dispersion calculation, $4 \mathrm{~b}$, that are absent in the $\Gamma$-point only calculation, $4 \mathrm{c}$, as the acoustic modes have zero energy at the $\Gamma$-point, Figure 5 a.

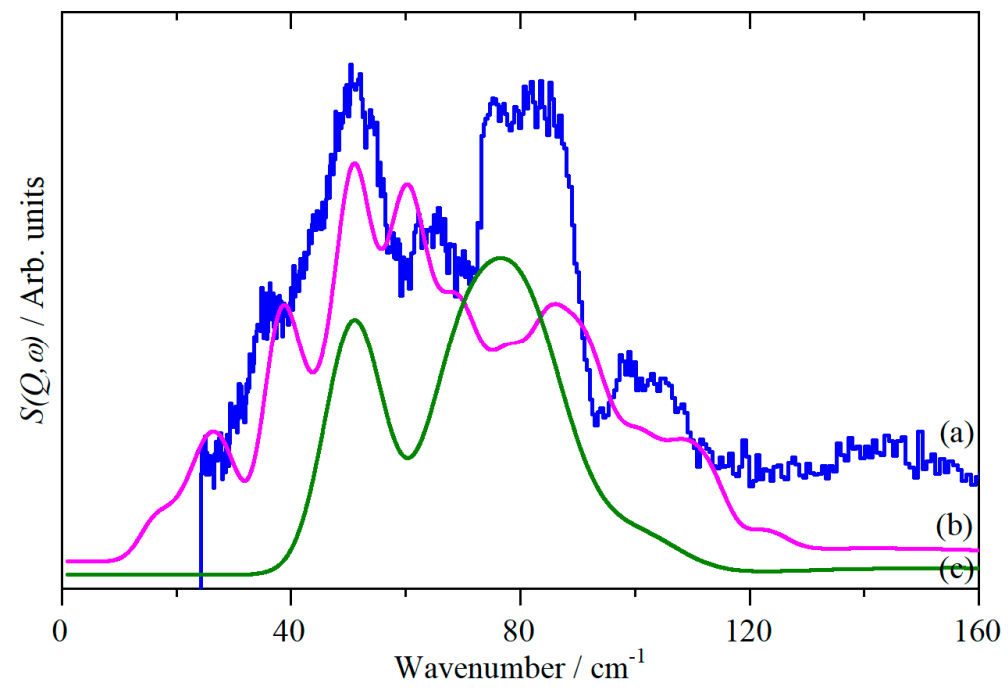

Figure 4. INS spectra of solid $\mathrm{CS}_{2}$ in the lattice mode region. (a) Observed, (b) generated from a periodic-DFT calculation for the complete Brillouin zone, and (c) as (b) but for the $\Gamma$-point only.
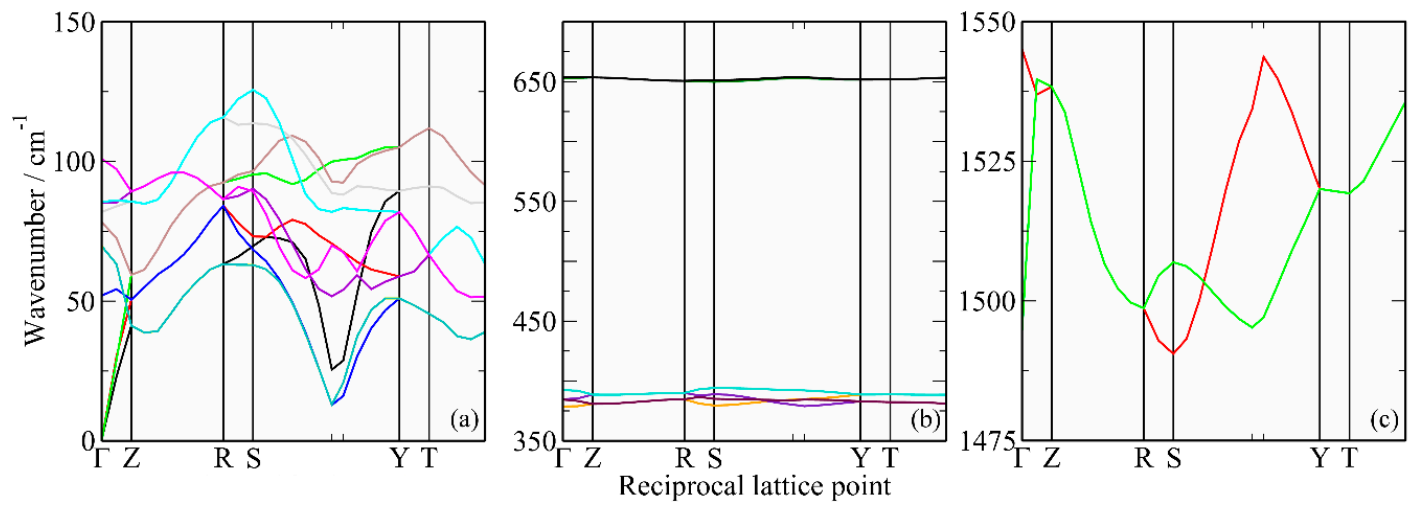

Figure 5. Calculated dispersion curves of solid $\mathrm{CS}_{2}$. (a) In the lattice mode region, (b) $v_{2}$ and $v_{1}$, and (c) $v_{3}$. 
The comparison of Figure $4 \mathrm{~b}$ and $4 \mathrm{c}$ also shows that the features at 99 and $104 \mathrm{~cm}^{-1}$, that have not been previously reported, are a consequence of the dispersion in the librational modes away from the $\Gamma$-point, Figure 5 a.

\section{Discussion}

The aim at the outset of this project was to locate the two infrared and Raman inactive factor group components of the translations and the $v_{2}$ bending mode. The expectation was that, because all the modes are allowed in the INS, this should enable their location, as has been done for many other systems, e.g., $\mathrm{C}_{60}[19]$ and $\mathrm{M}(\mathrm{CO})_{6}(\mathrm{M}=\mathrm{Cr}, \mathrm{Mo}, \mathrm{W})$ [20]. This has proven to be more complicated than anticipated. The width of an INS peak is determined by the instrumental resolution and the inherent peak width, which depends on the vibrational dispersion. All four of the $v_{2}$ bending mode components fall within $12 \mathrm{~cm}^{-1}$ and have a few wavenumbers dispersion, which accounts for the measured width (the resolution at this energy transfer is $\sim 5 \mathrm{~cm}^{-1}$ [13]). Based on a simulation of the band shape of the $390 \mathrm{~cm}^{-1}$ feature, the most likely position of the optically forbidden component of the $v_{2}$ bending mode is $393 \pm 2 \mathrm{~cm}^{-1}$.

The translational mode is much more problematic. The calculations, Figure 4a, show that this is strongly dispersed, so it does not result in a single feature in the INS spectrum. The calculated value of $52 \mathrm{~cm}^{-1}$ at the $\Gamma$-point is slightly higher than the $37 \mathrm{~cm}^{-1}$ measured close to the melting point of $\mathrm{CS}_{2}$ [11], but the latter is likely to be severely affected by anharmonicity.

\section{Materials and Methods}

Carbon disulfide (99\%) was purchased from Sigma-Aldrich (Gillingham, Dorset, UK) and used as received.

INS spectra were recorded using the TOSCA [21] spectrometer at the ISIS Pulsed Neutron and Muon Facility (Chilton, Oxfordshire, UK) [22]. On TOSCA, the resolution is $\sim 1.25 \%$ of the energy transfer across the entire energy range. Infrared spectra $\left(4 \mathrm{~cm}^{-1}\right.$ resolution, $\left.64 \mathrm{scans}\right)$ were recorded between $105 \mathrm{~K}$ and $298 \mathrm{~K}$ with a Bruker Vertex 70 Fourier transform infrared spectrometer using a Specac single reflection variable temperature attenuated total internal reflection accessory. The FT-Raman spectrum was recorded at room temperature and $77 \mathrm{~K}$ from the sample inside a quartz cuvette with a Bruker MultiRam spectrometer using $1064 \mathrm{~nm}$ excitation (500 mW laser power and 1024 scans at $4 \mathrm{~cm}^{-1}$ resolution).

Dispersion corrected periodic density functional theory (DFT-D) calculations were carried out using the plane wave pseudopotential method, as implemented in the CASTEP code (version 17.21) [23,24]. Exchange and correlation were approximated using the PBE [25] functional with the Tkatchenko-Scheffler (TS) dispersion correction scheme [26] within the generalized gradient approximation (GGA). The plane-wave cut-off energy was $750 \mathrm{eV}$. Brillouin zone sampling of electronic states was performed on a $12 \times 12 \times 4$ Monkhorst-Pack grid ( 84 k-points). The equilibrium structure, an essential prerequisite for lattice dynamics calculations, was obtained by BFGS geometry optimization after which the residual forces were converged to $\pm 0.00087 \mathrm{eV} \AA^{-1}$. Phonon frequencies were obtained by diagonalization of the dynamical matrix, computed using density-functional perturbation theory [27], to compute the dielectric response and the Born effective charges, and, from these, the mode oscillator strength tensor and infrared absorptivity were calculated. In addition to the calculation of transition energies and intensities at zero wavevector, phonon dispersion was also calculated along high symmetry directions throughout the Brillouin zone. For this purpose, dynamical matrices were computed on a regular grid of wavevectors throughout the Brillouin zone, and Fourier interpolation was used to extend the computed grid to the desired fine set of points along the high-symmetry paths [28]. The atomic displacements in each mode, that are part of the CASTEP output, enable visualization of the modes to aid assignments and are also all that is required to generate the INS spectrum using the program ACLIMAX (version 6.0.0 LE) [18]. It is emphasised that, for the calculated spectra and dispersion curves shown, the transition energies have not been scaled. 


\section{Conclusions}

This paper highlights the crucial interplay of theory and experiment for vibrational spectroscopy. Without the calculations, finding the location of the $A_{u}$ component of the $v_{2}$ bend quartet would be simply guesswork, as none of the three forms of vibrational spectroscopy enable observation of the mode, but it must contribute to the INS spectrum. Similarly for the $A_{u}$ translational mode, the calculations show this to be highly dispersed, so a distinct feature cannot be assigned to it. The comparison of the theory and the experiment for the INS spectra illustrates the power of the combination, but also demonstrates that DFT still has some way to go before it can predict intermolecular modes with the same reliability that it does for intramolecular modes.

Author Contributions: Conceptualization, S.F.P.; experimental work, F.A., M.A.F., F.O., R.R.W.; S.F.P; writing - original draft preparation, S.F.P; writing—review and editing, S.F.P, I.B.A.; funding acquisition, I.B.A. All authors have read and agreed to the published version of the manuscript.

Funding: This research was supported by the Science and Technology Facilities Council (STFC) and the Newton Fund.

Acknowledgments: The UK-Indonesia Science and Technology Partnership on STEM Skills for Large Facilities, supported by the Newton Fund and delivered by STFC, ISIS, Diamond, and LIPI is gratefully thanked for the financial support of this project. The STFC Rutherford Appleton Laboratory is thanked for access to neutron beam facilities. Computing resources (time on the SCARF computer cluster for the CASTEP calculations) was provided by STFC's e-Science facility. This research has been performed with the aid of facilities at the Research Complex at Harwell, including the FT-Raman spectrometer. The authors would like to thank the Research Complex for access and support to these facilities and equipment.

Conflicts of Interest: The authors declare no conflicts of interest.

\section{References}

1. Smith, D.E.; Timmermann, R.W. Carbon Disulfide. In Kirk-Othmer Encyclopedia of Chemical Technology, 4th ed.; John Wiley: New York, NY, USA, 1991; Volume 5, pp. 26-36.

2. Stoicheff, B.P. High resolution Raman spectroscopy of gases: XI. Spectra of $\mathrm{CS}_{2}$ and $\mathrm{CO}_{2}$. Can. J. Phys. 1958, 36, 218-230. [CrossRef]

3. Person, W.B.; Hall, L.C. Absolute infrared intensities of $\mathrm{CS}_{2}$ fundamentals in gas and liquid phases. An interpretation of the bond moments of $\mathrm{CO}_{2}$ and $\mathrm{CS}_{2}$. Spectrochim. Acta 1964, 20, 771-779. [CrossRef]

4. Smith, D.F.; Overend, J. General quartic force field of $\mathrm{CS}_{2}$. J. Chem. Phys. 1971, 54, 3632-3639. [CrossRef]

5. Lindenmayer, J.; Jones, H. Diode laser spectroscopy of the $v_{3}$ band region of four isotopic forms of $\mathrm{CS}_{2}$. J. Mol. Spec. 1985, 110, 65-73. [CrossRef]

6. Kroto, H.W.; Teixeira-Dias, J.J.C. The effects of intermolecular interactions in the Raman spectrum of liquid $\mathrm{CS}_{2}$. Spectrochim. Acta 1972, 28, 1497-1502. [CrossRef]

7. Anderson, A.; Grout, P.J.; Leech, J.W.; Sun, T.S. Raman spectra of molecular crystals: Carbon disulphide. Chem. Phys. Lett. 1973, 21, 9-14. [CrossRef]

8. Yamada, H.; Person, W.B. Absolute infrared intensities of the fundamental absorption bands in solid $\mathrm{CS}_{2}$. J. Chem. Phys. 1964, 40, 309-321. [CrossRef]

9. Ishi, K.; Takahashi, S.I. Far infrared spectrum of crystalline carbon disulphide. Chem. Phys. Lett. 1977, 45, 460-461. [CrossRef]

10. Burgos, E.; Righini, R. The effects of anisotropic atom-atom interactions on the crystal structure and lattice dynamics of solid $\mathrm{CS}_{2}$. Chem. Phys. Lett. 1983, 96, 584-590. [CrossRef]

11. Powell, B.M.; Dolling, G.; Torrie, B.H.; Pawley, G.S. Intermolecular modes of solid carbon disulphide. J. Phys. C: Solid State Phys. 1982, 15, 4265-4274. [CrossRef]

12. Bier, K.D.; Jodl, H.J.; Loewenschuss, A. The Raman spectrum of amorphous and crystalline solid carbon disulphide. Chem. Phys. Lett. 1985, 115, 34-39. [CrossRef]

13. Mitchell, P.C.H.; Parker, S.F.; Ramirez-Cuesta, A.J.; Tomkinson, J. Vibrational Spectroscopy with Neutrons, with Applications in Chemistry, Biology, Materials Science and Catalysis; World Scientific: Singapore, Singapore, 2005.

14. Baenziger, N.C.; Duax, W.L. Crystal structure and molecular motion of solid carbon disulfide. J. Chem. Phys. 1968, 48, 2974-2981. [CrossRef] 
15. Powell, B.M.; Dolling, G.; Torrie, B.H. Structure of solid carbon disulphide between 5 and 150 K. Acta Cryst. 1982, B38, 28-32. [CrossRef]

16. Grout, P.J.; Leech, J.W. Intermolecular modes of solid carbon disulphide. J. Phys. C: Solid State Phys. 1982, 15, L1083-L1087. [CrossRef]

17. Higgs, J.F.; Anderson, A. Dynamical model for the lattice frequencies and crystal field splittings of carbon disulphide. Phys. Stat. Sol. (b) 1986, 137, 39-46. [CrossRef]

18. Ramirez-Cuesta, A.J. aCLIMAX 4.0.1, The new version of the software for analyzing and interpreting INS spectra. Comput. Phys. Commun. 2004, 157, 226-238. [CrossRef]

19. Parker, S.F.; Bennington, S.M.; Taylor, J.W.; Herman, H.; Silverwood, I.; Albers, P.; Refson, K. Complete assignment of the vibrational modes of $\mathrm{C}_{60}$ by inelastic neutron scattering spectroscopy and periodic-DFT. Phys. Chem. Chem. Phys. 2011, 13, 7789-7804. [CrossRef]

20. Parker, S.F.; Jayasooriya, U.A. Assignment of the solid state spectra of the Group VI hexacarbonyls by inelastic neutron scattering spectroscopy. Phys. Chem. Chem. Phys. 2019, 21, 24950-24955. [CrossRef]

21. Pinna, R.S.; Rudić, S.; Parker, S.F.; Armstrong, J.; Zanetti, M.; Škoro, G.; Waller, S.P.; Zacek, D.; Smith, C.A.; Capstick, M.J.; et al. The neutron guide upgrade of the TOSCA spectrometer. Nucl. Instrum. Methods Phys. Res. A 2018, 896, 68-74. [CrossRef]

22. ISIS Neutron and Muon Source. Available online: http://www.isis.stfc.ac.uk/ (accessed on 24 March 2020).

23. Clark, S.J.; Segall, M.D.; Pickard, C.J.; Hasnip, P.J.; Probert, M.J.; Refson, K.; Payne, M.C. First principles methods using CASTEP. Z. Krist. 2005, 220, 567-570. [CrossRef]

24. Refson, K.; Tulip, P.R.; Clark, S.J. Variational density-functional perturbation theory for dielectrics and lattice dynamics. Phys. Rev. B 2006, 73, 155114. [CrossRef]

25. Perdew, J.; Burke, K.; Ernzerhof, M. Generalized gradient approximation made simple. Phys. Rev. Lett. 1996, 77, 3865-3868. [CrossRef] [PubMed]

26. Tkatchenko, A.; Scheffler, M. Accurate molecular van der Waals interactions from ground-state electron density and free-atom reference data. Phys. Rev. Lett. 2009, 102, 073005. [CrossRef] [PubMed]

27. Milman, V.; Perlov, A.; Refson, K.; Clark, S.J.; Gavartin, J.; Winkler, B. Structural, electronic and vibrational properties of tetragonal zirconia under pressure: A density functional theory study. J. Phys.: Condens. Matter 2009, 21, 485404. [CrossRef] [PubMed]

28. Gonze, X.; Charlier, J.-C.; Teter, M.P. Interatomic force constants from first principles: The case of $\alpha$-quartz. Phys. Rev. B 1994, 50, 13035-13038. [CrossRef]

Sample Availability: Carbon disulfide is widely available from commercial sources.

(C) 2020 by the authors. Licensee MDPI, Basel, Switzerland. This article is an open access article distributed under the terms and conditions of the Creative Commons Attribution (CC BY) license (http://creativecommons.org/licenses/by/4.0/). 